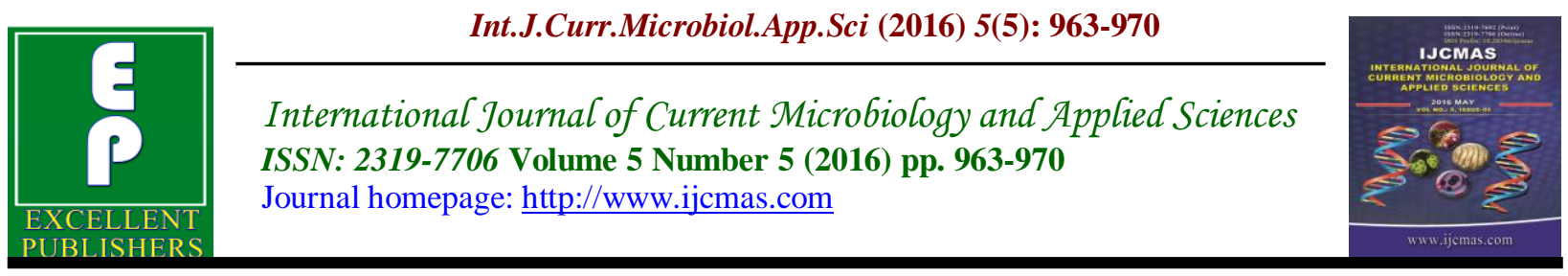

Original Research Article

http://dx.doi.org/10.20546/ijcmas.2016.505.101

\title{
Studies on the Multidrug Resistance to Pseudomonas aeruginosa Isolated from Infected Wounds
}

\author{
N.A. AL-Kadhmi ${ }^{1}$, A.N. AL-Thwaini ${ }^{2}$, W.A. AL-Turk ${ }^{3}$ and K.I. ALtaif ${ }^{3 *}$ \\ ${ }^{1}$ AL-Imamein AL-Kadhimein Medical city / Baghdad, Iraq \\ ${ }^{2}$ Genetic Engineering and Biotechnology institute for postgraduate studies / \\ University of Baghdad, Iraq \\ ${ }^{3}$ Faculty of pharmacy, Middle East University, Amman-Jordan \\ *Corresponding author
}

\begin{abstract}
A B S T R A C T
Keywords

Pseudomonas,

Resistance,

Wounds,

PCR,

MBL.

\begin{tabular}{l}
\hline Article Info \\
\hline Accepted: \\
18 April 2016 \\
Available Online: \\
10 May 2016
\end{tabular}

The infection wounds remain challenging and present a major global problem leading to many complications. All collected samples, 150 swab from patient's wounds and hospital units were cultured on different media and tested biochemically. The profile of bacteria in the cultured samples revealed that, Staphylococcus aureus was the most common bacteria and represented in 23 isolates (18\%), followed by Pseudomonas aeruginosa with 11 isolates (12\%). The results showed that, all isolates were completely (100\%) resistant to Ceftrixone, Cefepime, Ampicillin-Sulbactam, and Ceftazidime. Psedomonas aeruginosa showed the highest resistance to both Gentamycin, TrimethoprimeSulfamethoxazole reached to $66.6 \%$ and to less extent against Aztreonam (61.1\%). Polymerase Chain Reaction (PCR) was used to detect some of Metallo Beta Lactemase MBL genes responsible for antibiotic's resistance in $P$. aeruginosa isolates as, blaVIM and bla IMP. The results showed that six isolates of $P$. aeruginosa carried bla VIM, two had bla IMP.
\end{abstract}

\section{Introduction}

The wounds infection remains challenging and major global problem, leading to many complications and increased both morbidity and mortality among hospitalized patients (Raza et al., 2013). Most of wounds are subsequently colonized with microorganisms, including Gram-positive and Gram-negative bacteria and yeasts, which probably derived either from hosts normal flora and/or the hospital environment (Chen, et al., 2011).
Data from various medical records, revealed that Pseudomonas aeroginosa, Staphylococcus auerus, Escherichia coli and Acinetobacter spp. are among the most common pathogens associated with wound infections (Hujer, et al., 2006; Birgy, et al., 2012). Pseudomonas species are common gram-negative non fermenter opportunistic bacteria associated with nosocomial infections, especially in immunocompromised patients (Vahdani, et al., 
2012), as well as in soliders with infected wounds, surgical wounds (Agency, 2003) and patients suffering from diabetic foot ulcers (Boulton, et al., 2006; Sharma, et al., 2006).

Increasing rates of antibiotics resistance among bacteria is a major concern worldwide and the most common mechanisms of this resistance are the production of $\beta$-lactamases, including classes A, D and B enzymes (Walsh, et-al. 2005). These enzymes are encoded either by genes that are a part of bacterial chromosome or by heterologous genes acquired by transfer of mobile genetics elements, therefore acquired MBLs could be spread among various strains of bacteria such as P.aeruginosa (Walsh, et al 2005) Approximately, six different types of acquired MBL have been defined, and these enzymes are (VIM), (IMP), (GIM), (SPM), (KPC) and NDM (Samuelson, et al., 2010; Cornaglia, et al., 2011).

Studies by Sheikh et al. (2014) on MBL producing P.aeruginosa in burns and non burns patients using polymerase chain reaction (PCR) technique demonstrated that only one isolate harboring bla VIM while most of the other positive isolates for MBL genes were bla IMP positive PCR analyses was performed for all the P.aeruginosa isolates and bla IMP and bla VIM genes were detected in $11.7 \%$ and $0.4 \%$ of the isolates, respectively (Sheikh, et al., 2014).

The present study aimed to estimate the incidence of P.aeruginosa in patients suffering from infected wounds who were hospitalized in Al- Imamein Al-Kadhimein Medical city, Baghdad, and to determine the presence of multidrug resistant isolates of P.aeruginosa. In addition, a molecular detection of bla VIM and bla IMP genes that are responsible for $\beta$-lactam carbapenemases resistance in multidrug resistant isolates will also be investigated.

\section{Materials and Methods}

\section{Subjects}

The study was conducted on 75 swabs collected from patient's wounds, both males and females of different age. The younger patient was six years old and the oldest patient was seventy five years old, for the period from the end of June 2015 to end of September 2015 in Al-Imamein AlKadhimein Medical city in Baghdad. The patients were divided into four groups according to age.

\section{Bacterial Identification}

The bacteria were diagnosed and the identification was carried out through routine test:

Culturing on different types of media.

Biochemical test, by using AP120E system, according to Jawetz, et al. (2007) for confirmation.

\section{Antimicrobial Susceptibility Test}

Antimicrobial susceptibility testing performed by Kirby-Bauer disc diffusion method according to Bauer, (1966), on Muller-Hinton agar. Thirteen antibiotics were tested which were: Ampicillinsulbactam, Ceftriaxone, Ceftazidime, Imipenem, Aztreonam, Piperacillin, Cefepime, Amikacin, Gentamicin, Trimethoprime-salfamethoxazole, Ciprofloxacin, Levofloxacin and Doxycycline.

\section{Molecular Assays}

\section{DNA Extraction}

Chromosomal DNA was extracted from culture of P.aeruginosa by using Genomic 
DNA kit according to the instruction of manufacturing company (Wizarrd, USA), to extract bla VIM and bla IMP genes in P.aeruginosa by using specific primers as shown in table 1.

\section{PCR Protocol}

PCR protocol which included initial denaturation at $95 \mathrm{C}$ for $4 \mathrm{~min}$, followed by 30 three-step cycles, including denaturation at $94 \mathrm{C}$ for $1 \mathrm{~min}$, annealing at $51 \mathrm{C}$ for 1 min, extension at $72 \mathrm{C}$ for $1 \mathrm{~min}$. and a final extension at $72 \mathrm{C}$ for $5 \mathrm{~min}$ as shown in table 2

\section{Statistical Analyses}

Statistical Analysis System program was used for the analysis of data.Ch-square $\left(\mathrm{X}^{2}\right)$ test was used to test the significance compare between percentage in this study (SAS, 2012).

\section{Results and Discussion}

Wounds infection is a complex process that results from a detrimental interaction between the host and the pathogens (Wilson, et al., 2004; White, 2009).

The total number of swabs samples in this study was (75) divided according to age in to four groups as shown in table 3.

The results revealed that the highest number of patients were located in age group 21-35 years $(n=39 ; 52 \%)$ while the lowest number was observed in age group 6-20 years $(9.3 \%)$. The results also indicated that the highest incidence was among male subjects than female (Fig 1).

In fact, this was not unexpected results, since male do usually practice hard work and are exposed to different kinds of accident especially the soldiers.

\section{Culture Results of Patients Wounds}

Different bacterial species of Gram positive and Gram negative microorganism were isolated and identified. The results showed that positive culture were (43) single bacterial isolated, while the remainder (14) was with bacterial growth. These results demonstrated that S.aureus was among the most common isolate (23 isolates $30.7 \%$ ) followed by P.aeruqinosa (11 isolates, $14.6 \%$ ). This was in accordance with similar results of a study on 100 swab of patient's wounds in Iraq (Al-Azawi, 2013) who found that $88 \%$ were culture positive and $12 \%$ were negative. S.aureus isolated were 34 (38.6\%), followed by E.coli and P.aeruginosa were $28(31.8 \%)$ and 24 $(27.3 \%)$ respectively. On the other hand, the findings of Masaadeh and Jaran (2009) in Jordan showed that most the 115 isolated post-operative wounds infection were with P.aeruginosa (27.8\%) followed by E.coli $(15.6 \%)$ and $\mathrm{S}$. aureus (14.7\%).

\section{Antibiotic Susceptibility Test for Pseudomonas aeruginosa}

The antibiogram of studied isolates revealed that all P.aeruginosa isolates (clinical and environmental) were $(100 \%)$ resistant to Ceftrixone, Cefepime, Ampicillin Sulbactam and Ceftazidime, and the present isolates appeared to be highly resistant against to both Gentamycin and Trimethoprime which reached to $66.66 \%$, and it was $61.11 \%$ against Aztreonam, while it was55. 5\% for each of Amikacin, Piperacillin and Doxycycline. Furthermore, half of the isolates were resistant to Levofloxacin. However, the isolates showed good sensitivity to Ciprofloxacin reached to $61.1 \%$, and high sensitivity to Imipenem reached to $(77.8 \%)$. These findings were in agreement with those published by AL Kassi et al. (2015) who isolated different 
types of bacteria from burn's patient and units of hospital in Baghdad, which had shown that P.aeruginosa isolates appeared to show complete resistance $(100 \%)$ to Ceftraixone, Cefepime and high resistance to Gentamicin, Ceftazidime and Pipracillin (93.3\%, 88.3\% and 86.\%) respectively. Furthermore, $86 \%$ of isolates were sensitive to Imipenem and this was higher than the results of our study, while another study by Al -Kaabi, (2013) reported that all bacterial isolates from burns patients were tested against 19 antibiotics, and showed multidrug resistance to 10 antibiotics, and found that the most effective antibiotics were the fifthgeneration Cephalosporin, Ceftobiprole, and antibiotic combinations, as Ceftazidime / Clavulanic acid, and Cefoperazone /Sulbactam, and newer generation Fluoroquinolone Levofloxacin, and Gemifloxacin.

Table.1 The Sequence Forward and Reverse Primers of bla VIM and bla IMP genes

\begin{tabular}{|c|c|c|c|}
\hline $\begin{array}{l}\text { Primer } \\
\text { Name }\end{array}$ & $\begin{array}{l}\text { Sequence } \\
5^{\prime} \stackrel{3}{\longrightarrow} 3^{\prime}\end{array}$ & \begin{tabular}{|l|} 
Detected \\
Gene
\end{tabular} & $\begin{array}{l}\text { Product Size } \\
\text { (bp) }\end{array}$ \\
\hline blaVIM-F & TTTGGTCGCATATCGCAACG & \multirow{2}{*}{ blaVIM } & \multirow{2}{*}{$500 \mathrm{bp}$} \\
\hline baVIM-R & CCATTCAGCCAGATCGGCAT & & \\
\hline blaIMP-F & GTTTATGTTCATACWTCG & \multirow{2}{*}{$b^{\prime} a_{\mathrm{IMP}}$} & \multirow{2}{*}{ 432bp } \\
\hline blaIMP-R & GGTTTAAYAAAACAACCAC & & \\
\hline
\end{tabular}

Table.2 PCR Protocol for bla (VIM and IMP) Gene Amplification

\begin{tabular}{|l|l||l||l||l|}
\hline No. & Steps & Temperature $\left({ }^{\circ} \mathbf{C}\right)$ & Time & Cycles \\
\hline 1. & Initial Denaturation & 95 & 4 min & 1 \\
\hline 2. & Denaturation & 94 & 1 min & \\
\hline 3. & Annealing & 51 & 1 min & 30 \\
\hline 4. & Extension & 72 & 1 min & \\
\hline 5. & Final extension & 72 & 5 min & 1 \\
\hline
\end{tabular}

Table.3 The Prevalence and Percentage of Infected Wounds in Different Age Groups

\begin{tabular}{|l|l|l|}
\hline Age lyear & No. of cases & Percentage \\
\hline $6-20$ & 7 & 9.3 \\
\hline $21-35$ & 39 & 52.0 \\
\hline $36-55$ & 19 & 25.3 \\
\hline $56-75$ & 10 & 13.3 \\
\hline
\end{tabular}


Fig.1 Distribution of Patient's Wounds According to Gender

Fig.2 Susceptibility of $P$. aeruginosa to Various Antibiotics by Disc-Diffusion Method.

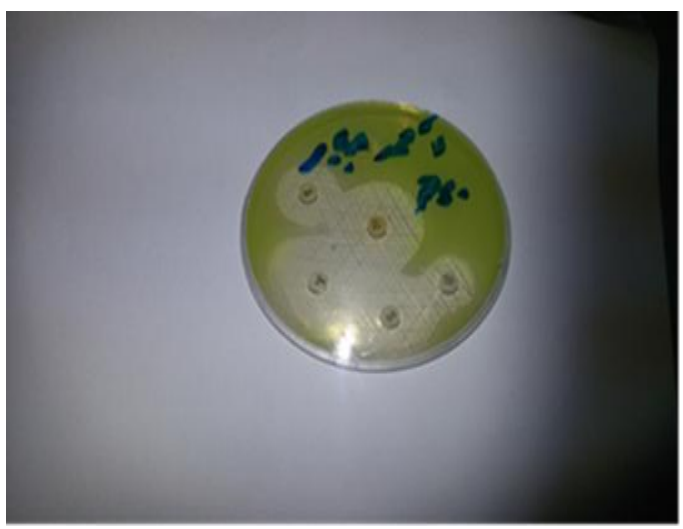

Fig.3 Extracted DNA Electrophoresis on $1 \%$ agarose (70 vol/ 30min) to Check Purity and Integrity

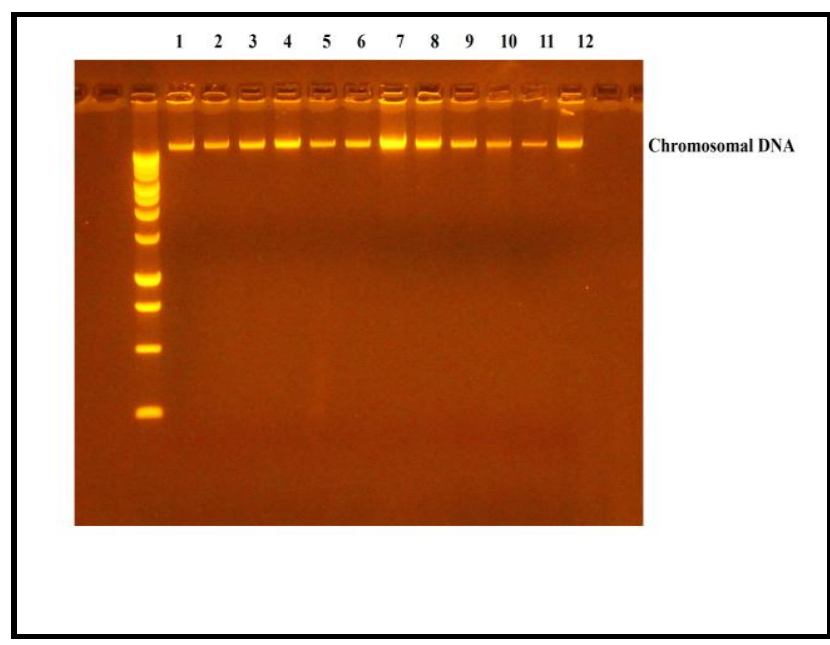


Fig.4 Gel Electrophoresis of PCR Product for Detection of MBLsblaVIM gene (500 bp) in Pseudomonas aeruginosa using 1\% Agarose for $90 \mathrm{~min}$. at $70 \mathrm{~V} / \mathrm{cm}$. (1) M: Marker DNA ladder Size (100bp). (2) Lanes 16,18, 24 and 26 Pseudomonas aeruginosa isolates

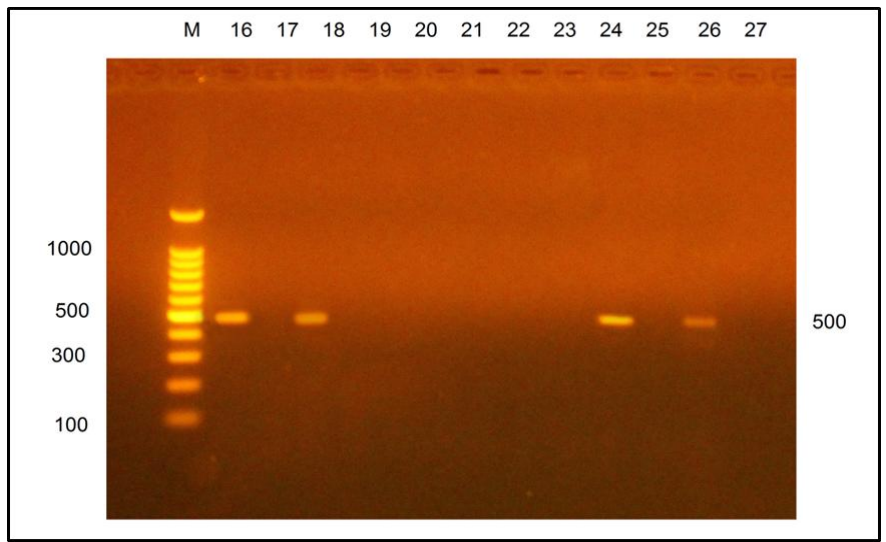

Fig.5 Gel Electrophoresis of PCR Product for Detection of MBLsblaIMP Gene (432) from Pseudomonas aeruginosa, using $1 \%$ agarose for $90 \mathrm{~min}$. at $70 \mathrm{~V} / \mathrm{cm}$. (1)M: Marker DNA ladder Size (100bp). (2) Lanes 5-6 Pseudomonas aeruginosa isolates

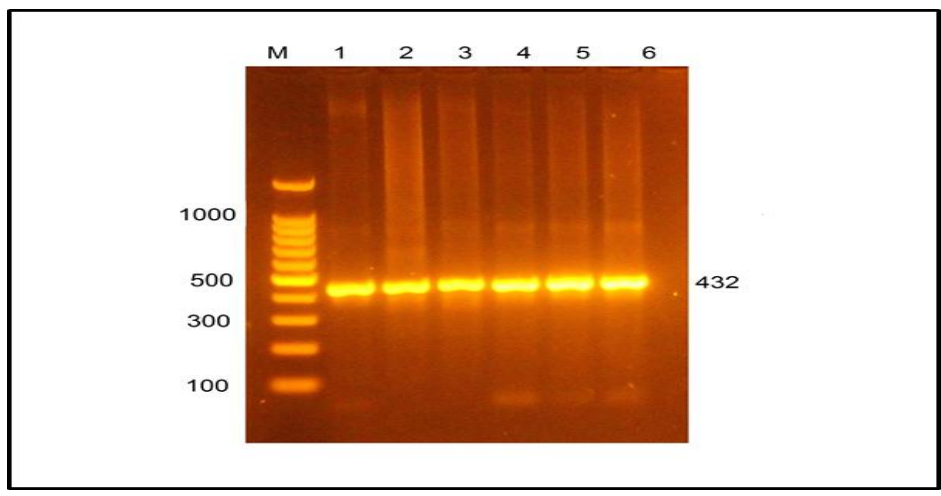

The current study noticed that Ciprofloxacin has been reported as the second most effective drugs against P.aeruginosa with sensitivity reached to $61.11 \%$ this well agreed with the study conducted by Kaushik et al. (2001) in India.

Antibiotic resistance is a major concern of contemporary medicine. The continuing emergence of resistance strain that cause nosocomial infection contribute substantially to the morbidity and mortality among hospitalized patients (Harris et al., 1999; Aloush et al., 2006).
Molecular Detection of MBLs Genes (bla VIM and bla IMP) in Pseudomonas aeruginosa and Isolates

In the present study, DNA extracted from 11 isolates of P.aeruginosa. DNA concentration and purity were measured by the DNA extraction kit and the results revealed that DNA concentration as (50-100 ng) and purity of DNA as (1.5-1.8). The DNA was detected by gel electrophoresis which appeared as single and clear bands Figure 3. 


\section{PCR Analysis}

PCR technique was used to detect genes of 11 isolates, which were, blaVIM gene and bla IMP, that were responsible for carbapenemase-resistant antibiotic (Fig. 4 \& 5 ). The result of PCR revealed that, the bla VIM gene $(500 \mathrm{bp})$ was detected only in 6 isolates from total 11 isolates, that represented $(22.2 \%)$ with significant difference $(\mathrm{P}<0.05)$. In addition, six isolates of $P$. aeruginosa carried bla VIM, two from them had bla IMP. These findings were in agreement with a recent study of Khorrash, etal. (2015) which found that amplification of $\beta$-lactamase, blaVIM genes in $7(14.6 \%)$ strains of P.aeruginosa.

In conclusion, P.aeruginosa was the most common Gram negative bacteria isolated from different types of wounds that was highly resistant to different types of antibiotics.

\section{Acknowledgement}

The authors would like to thanks Prof. Emad Al-Dujaili, Middle East University for reviewing the manuscript.

\section{References}

Agency, H.P. 2003. A prevalent strain of Acinetobacter baumannii. Common Dis. Rep. CDR Weekly, 13: 29-33.

AL Azawi, Z. 2013. Antimicrobial Susceptibility Patterns of Aerobic Bacterial Species of Wound Infections". Diyala, J. Med. Sine, Vol. 4, Issue-1.

Al-Kaabi, S.A. 2013. Bacterial Isolates and Their Antibiograms of Burn Wound Infections in Baghdad. Sci. J., 10: 331-339.

AL -Kassi, A., AL - Thwani, A., AL-Segar, R. 2015. PCR detection of some
ESBLS genes in Pseudomonas aeruginosa isolated from Burn's units in Baghdad hospital Baghdad". J. Biotechnol. Res. Center, 9(2): 74.

Aloush, V., Navon, S., Seigman-Igra, W., Capili, S., Carmeli, W. 2006. Multidrug resistance Pseudomonas aeruginosa : risk factors and clinical impact. Antimicrob. Agent Chemother., 50: 43-48.

Bauer, A., Kirby, W., Sherris, J., Turck, M. 1966. Antibiotic susceptibility testing by a standardized single disk method. Am. J. Clin. Pathol., 45(4): 493-496.

Birgy, A., Bidet, P., Genel, N. 2012. Phenotypic screening of carbapenemases and associated betalactamases in carbapenem-resistant Enterobacteriaceae". J. Clin. Microbiol., 50: 1295-302.

Boulton, A.J., Vileikyte, L., Ragnasron, Tennvall, G.A., Pelqvist, J. 2006.The global burden of diabetic foot disease". Lancet, 366: 1719-1724.

Chen, Y., Zhou, Z., Jiang, Y. 2011. Emergence of NDM-1-producing Acinetobacter baumannii in China.". J. Antimicrobial Chemother., 66: 1255-9.

Cornaglia, G., Giamarellou, H., Rossolini, G.M. 2011. Metallo- $\beta$-lactamases: a last frontier for $\beta$-lactams? Lancet Infect. Dis., 11: 381-393.

Harris, A., Torres-Viera, C., Venkataraman, L., DeGirolami, P., Samore, M. Carmeli, Y. 1999. Epidemiology and clinical outcomes of patients with Pseudomonas aeruginosa. Clin. Infect. Dis., 28: 1128-33.

Hujer, K.M., Hujer, A.M., Hulten, E., Bajaksouzian, S., Adams, J.M., Donskey, C.J., Bonomo, R. 2006. Analysis of antibiotic resistance genes in multidrug-resistant Acinetobacter $\mathrm{sp}$. isolates from military and civilian patients treated at the Walter Reed 
Army Medical Center. Antimicrob. Agents and Chemother., 50: 4114-23.

Jawetz, E., Melnick, J., Adelberg, E. 2007.

Med Microbial, 24nd ed. Appleton and Lange USA., Pp 263-288.

Kaushik, R., Kumar, S., Sharma, R., Lal, P. 2001. Bacteriology of Burn wound the first three years in a new Burn Unit at the Medical College of Chandigarh. Burn, 27: 595-597.

Khorrash, F., Reza, M., Shabani, S., Alizadeh, H. 2015. Detection of Pseudomonas aeruginosa producing Metallo $\beta$ Lactamases (VIM, SME, AIM). In the clinical Isolate of Intensive Care Unite of AL-Zahra Hospital in Esfahan, Iran. J. Med. Bacteriol., 4: Pp 16-24.

Masaadeh, H.A., Jaran, A.S. 2009. Incident of Pseudomonas aeruginosa in postoperative wound infection." Am. J. Infect. Dis., 5: 1-6.

Raza, M., Chander, A., Ranabhat, A. 2013. Antimicrobial susceptibility patterns of the bacterial isolates in postoperative wound infections in a tertiary care hospital, Kathmandu, Nepal. OJMM, 3: 159-163.

Samuelson, O., Toleman, M.A., Sundsfjord, A., Rydberg, J., Leegaard, T.M., Walder, M., Lia, A., Ranheim, T.E., Rajendra, Y., Hermansen, N.O., Walsh, T.R., Giske, C.G. 2010. Molecular epidemiology of metallo- $\beta$ lactamase-producing Pseudomonas aeruginosa isolates from Norway and Sweden shows import of international clones and local clonal expansion. Antimicrob Agents Chemother., 54: 346-352. Statistical Analysis System (SAS), (2012). Personal computer.ver.Q.I.Cary, NC.USA.

Sharma, M., Taneja, N. 2007. Burns, antimicrobial resistance and infection control". The Indian J. Med. Res., 126: 505-507.

Vahdani, M., Azimi, L., Asghari, B. 2012. Phenotypic screening of extendedspectrum s-lactamase and metallobeta-lactamase in multidrug-resistant Pseudomonas aeruginosa from infected burns". Ann. Burns Fire Disasters, 25: 78-81.

Walsh, T.R., Toleman, M.A., Poirel, L., Nordmann, P. 2005. Metallo- $\beta$ lactamases: the quite before the storm, Clin. Microbiol. Rev., 18: 306-325.

Sheikh, A., Rostami, S., Jolodar, A., Amin, M., Tabatabaiefar, A., Khorvash, F., Saki, A., Shoja, S., Sheikhi, A. 2014. Detection of Metallo- $\beta$ Lactamases Among Carbapenem-Resistant Pseudomonas aeruginosa Jundishapur. J. Microbiol., 7(11): e12289.

White, R. 2009. Wound infection-associated pain. J. Wound Care, 18: 245-49.

Wilson, A., Gibbons, C., Reeves, B., Hodgson, B., Liu, M., Plummer, D. 2004. Surgical wound infections as a performance indicator: agreement of common definitions of wound infections in 4773 Patients. B.M.J., 329: $720-722$.

\section{How to cite this article:}

AL-Kadhmi, N.A., A.N. AL-Thwaini, W.A. AL-Turk and ALtaif, K.I. 2016. Studies on the Multidrug Resistance to Pseudomonas aeruginosa Isolated from Infected Wounds. Int.J.Curr.Microbiol.App.Sci.5(5): 963-970. doi: http://dx.doi.org/10.20546/ijcmas.2016.505.101 